\title{
Commentary: The narwhal of surgery: Dual cardiac surgeon families
}

\author{
Jennifer C. Romano, MD, MS
}

I applaud Gemmato and Baldwin for their candor in their article on work-life balance. ${ }^{1}$ Women interested in pursing a career in cardiothoracic surgery need to see others who have built careers and families despite the obstacles. I have been very transparent in my successes and struggles as a congenital heart surgeon with 2 young kids and an adult cardiac surgeon husband. Recently, a former trainee told me how meaningful it was that I brought my infant son to teaching conferences and shared stories of my family at work. It helped him, when struggling to balance a dual-career household, feel comfortable bringing his young child to weekend rounds. He found the experience incredibly positive for himself, his child, and those he worked with who had the opportunity to see him fully as an individual. As a result, he built far more meaningful relationships with colleagues. This amplifies the importance of work-life balance that has become more openly discussed and valued and has benefitted both genders. Individuals who nurture their personal well-being and interests are highly productive, healthier, more collaborative, and better mentors. To be dedicated and valued by your profession no longer requires marginalizing other facets of your life.

A JAMA survey reported $90 \%$ of married female resident physicians are in dual-career households with $50 \%$ being 2 physician households ${ }^{2}$ compared with only $13 \%$ of male surgeons in dual-career households. ${ }^{1}$ It is important to note that the $50 \%$ of women with a 2-physician household have a partner who is also a physician who is juggling similar responsibilities. It takes a village to navigate unpredictable operating schedules and the unexpected playground injury at school. Gemmato and Baldwin highlight the challenges while

\footnotetext{
From the Departments of Cardiac Surgery and Pediatrics, University of Michigan, Ann Arbor, Mich.

Disclosures: The author reported no conflicts of interest.

The Journal policy requires editors and reviewers to disclose conflicts of interest and to decline handling or reviewing manuscripts for which they may have a conflict of interest. The editors and reviewers of this article have no conflicts of interest.

Received for publication Oct 14, 2020; revisions received Oct 14, 2020; accepted for publication Oct 15, 2020; available ahead of print Oct 28, 2020.

Address for reprints: Jennifer C. Romano, MD, MS, 1540 E Hospital Dr, SPC 4204, Ann Arbor, MI 48109-4204 (E-mail: jhirsch@umich.edu).

J Thorac Cardiovasc Surg 2022;163:186

$0022-5223 / \$ 36.00$

Copyright (c) 2020 by The American Association for Thoracic Surgery

https://doi.org/10.1016/j.jtcvs.2020.10.069
}

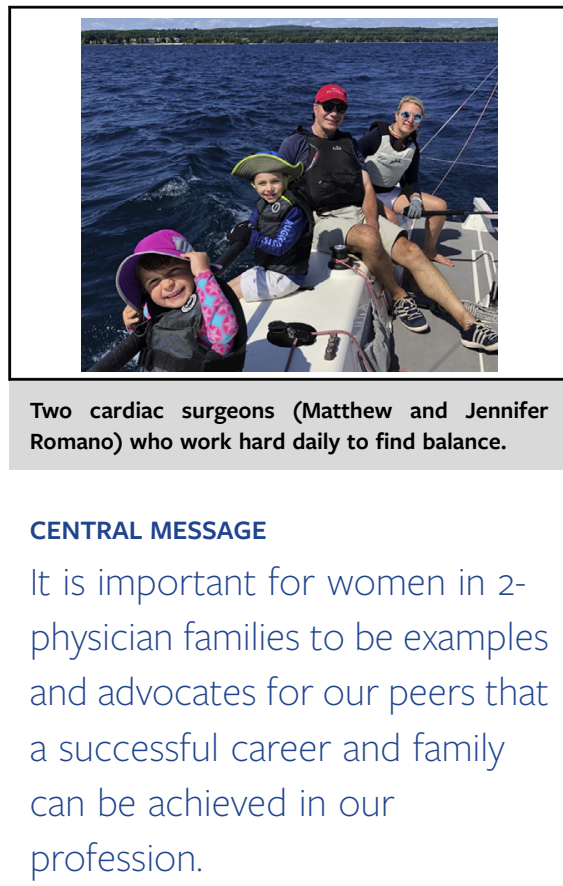

providing hope and optimism. The largest part of making it work is the commitment that your family is a priority.

The needs of dual-career households will be an increasing issue in our profession as the number of female cardiothoracic surgeons rises. Consider this a call to action to be thoughtful regarding training paradigms as well as career options for 2-physician families. I am pleased to highlight that as female cardiothoracic surgeons achieve positions of leadership, notable progress has been made to support young surgeons with families. The Society of Thoracic Surgeons Annual Meeting provides fully equipped lactation rooms. The American Board of Thoracic Surgeons has a parental (maternal or paternal) leave of absence policy that allows resident physicians 6 weeks of leave, independent of vacation time, with no penalty on duration of training.

More than ever, the field of cardiothoracic surgery is embracing the value women and diversity have brought to the profession. In addition to tremendous talent and leadership, women have placed the challenges and benefits of finding balance at the forefront that will make us all better going forward.

\section{References}

1. Gemmato CJ, Baldwin CW. Yes, we are both cardiac surgeons: one family's unique perspective on work-life balance. J Thorac Cardiovasc Surg. 2022;163:179-83.

2. Rangel EL, Smink DS, Castillo-Angeles M, Kwakye G, Changala M, Haider AH, et al. Pregnancy and motherhood during surgical training. JAMA Surg. 2018;153: 644-52. 